\title{
Planning and evaluating communications in an integrated organisation
}

Received: 15th February, 2006

\begin{abstract}
Angus Jenkinson
is Professor of Integrated Marketing at the Centre for Integrated Marketing, University of Luton Business School, and the founder and CEO of Stepping Stones Consultancy Ltd. He has made a significant contribution to practical thought leadership in integrated marketing, CRM and one-to-one marketing, and in integrated, media-neutral communications, for over 20 years, with over 100 publications and briefings. Firsts include a wide range of marketing tools now in everyday global practice, including the pen portrait/customer community tool 'CustomerPrints' and 'CRM-based touchpoint management'. He was formerly CEO of The Computing Group (when it was European CRM market leader) and before that General Manager/Marketing Director of JBA International plc, the industry-tailored ERP market leader. His clients include Barclays, IBM, ICG, Masterfoods, MediaEdge:ClA, OgilvyOne, Olympus, Novartis, the National Trust and Vodafone.
\end{abstract}

\begin{abstract}
Based on extensive research with practitioners across all sectors, this paper advises on how to execute integrated, media-neutral communications planning ('open planning') linked to integrated marketing. It also discusses current challenges and dysfunctionality in communication planning and evaluation, and suggests that a universal, open planning method would enhance planning, execution and evaluation.

Journal of Targeting, Measurement and Analysis for Marketing (2006) 15, 47-64. doi:10.1057/palgrave.jt.5750031
\end{abstract}

\section{INTRODUCTION}

Louis V. Gerstner Jr, the former CEO of IBM responsible for its turnaround, recounts how employees were first asked to wear white shirts and dark suits by their legendary leader, Tom Watson, because this was the clothing of the senior managers to whom they were talking. ${ }^{1}$ The intention was for salespeople to share the values of their customers. Over the decades, the customers changed, but IBM's dress became a uniform code that both defined IBM and separated it from its customers. This story illustrates the principle that to remain true to values often requires changes to execution. There is evidence that many marketers believe this applies today to marketing communications (marcoms). Indeed, this paper is based on results involving hundreds of interviews and several years of work with a wide variety of senior marketers

Correspondence: Angus Jenkinson, CEO, Stepping Stones Consultancy Ltd, Grange Farm Barn, Upper Dean, PE28 OLT, UK

Tel: + 44 (0)845 6588856;

E-mail: angus.jenkinson@stepping-stones.org in successful brands who want to solve their problems.

People establish common meaning and understanding and, therefore, relationships through communications. ${ }^{2}$ This is a basic tenet of marketing and branding, with each brand interaction constituting an act of communication. ${ }^{3}$ Consistent, coherent and congruent messages have positive effects, while mixed, contradictory or confused messages are dysfunctional, diluting the message or creating negative ideas about the brand.

The development of marcoms' disciplines and discipline-specific skills was aimed at more effective and efficient communications. For example, the development of the 'direct industry' and the Institute of Direct Marketing (IDM) in the 1980s helped to achieve this in one discipline. This story is complex but includes an element of competition and rivalry between the various media and disciplines. (Here, media are understood as the conduits of communication, such as radio and television, and disciplines as the 
creative and functional types of communication, such as sales promotion and direct marketing both terms will be discussed in more detail.)

\section{Developments in communication practice and theory}

One consequence is a recognised difficulty in establishing a coherent and consistent methodology, as well as a common framework for communication planning and evaluation., ${ }^{4,5}$ The previously dominant marcoms ideology ${ }^{6-8}$ produced discipline-specific teams, departments, agencies and cultures with consequences for efficiency, mutual understanding and communication-mix planning and evaluation. ${ }^{9-11}$

The transformation in the media landscape arising from the proliferation of lower reach/ highly targeted options and reduction in mass communication opportunities increases the need for effective communication planning and evaluation methods and tools. ${ }^{12,13}$ One feature of the change, which has become increasingly prevalent since the introduction of the concept of integrated marketing communications (IMC) in the early 1990s, is an increased emphasis on 'integration' and, more recently, 'media neutrality', with many brands and agencies reorganising practices in response to fragmentation and thinner segmentation, as well as recognition of the perceived benefits of integration. ${ }^{14-20}$ Practitioner changes are evidenced by the Institute of Practitioners in Advertising (IPA's) addition, in 2002, of 'reporting and understanding of integration (advertising in collaboration rather than competition with other disciplines)' to their awards submissions.

The essence of IMC is generally to create communication synergies and message amplification by combining, integrating and harmonising elements of the marketing communication mix. 'Media neutral' planning, which aims to optimise communication mix by eliminating bias and other suboptimising factors, is a further consequence..$^{21-23}$ Neutrality focuses on mix optimisation, while integration promotes consistency and harmony, and creative communication effects. To some extent, these concepts are aligned with notions of 'media' and 'creativity', but excessive focus on this differentiation would be misleading, as the choice of media, in practice, involves not only economic rigour but also creative consideration. ${ }^{24}$

Furthermore, although the term 'media neutral planning' emphasises 'media', it is clear that the planning challenge applies to more than just the limited set of paid-for advertising media. Indeed, this is central to the new technical challenges in implementation. Beyond media, practitioners are also concerned with choice of 'disciplines' - that is, the communications method or tool used with the medium - and therefore the people/agencies with skills in their application. Thus, direct response television has a different emphasis from classic television-based image advertising. Jenkinson and Sain ${ }^{25}$ propose the term 'channel' to mean the fusion of a communication discipline (advertising direct, public relations, etc) with a medium, where media consist of every contact that conveys a message to an audience.

Furthermore, they show how multiple disciplines can play a role in a single communication event (such as a mail pack).

The need for better management of individual customers and customer interfaces also encouraged marketers to develop customer relationship management (CRM) and relationship marketing practice. ${ }^{26}$ The drivers of these developments include improved opportunities to manage customer information, ${ }^{27-31}$ the need for reinforced loyalty and customer equity ${ }^{32-34}$ and the importance of brand equity, ${ }^{35-37}$ although brand equity (the enhancement of financial value gained by loyalty to a brand) and customer equity (based on earlier concepts of goodwill and lifetime value) are reciprocal and in some ways equivalent concepts.

\section{Integration}

Practitioners and theorists agree, however, that these initiatives cannot be separated; indeed, fusion is sought. ${ }^{38}$ As a result, the concept of integrated marketing has come into use. In some cases, this represents what Shultz and Kitchen ${ }^{39}$ describe as fourth-generation IMC involving financial and strategic integration; or a communications-oriented approach that blends 
IMC and CRM disciplines. ${ }^{40,41}$ Alternatively, it is seen as a larger discipline that involves organisation-wide synergies developing congruent, sustainable and high-value, differentiated brand experience for all stakeholders, as in the Jenkinson and Sain definition. ${ }^{42}$ Thus, integrated marketing has a role not only in the optimal recruitment and retention of customers, but also of employees and shareholders. ${ }^{43}$ This may be more briefly described as: integrated marketing is the organisationwide optimisation of unique value for stakeholders. According to Jenkinson et al., ${ }^{44}$ successful integrated marketing requires management of three business drivers made coherent by powerful ideas (the management drivers model):

- identity, which is seen as the core strategic element of differentiated value;

- mobilisation of all employees behind identity and value;

— integrated contact management.

Research by Jenkinson et al. ${ }^{45}$ among 200 UK senior marketers identified four sets of statistically robust operational competencies that drive customer experience and integrated marketing performance (the competencies model), with six operational factors constituting 50 per cent of customer experience (the BECAUSE factor):

- Living the brand involves employee participation and an aligned value stream, as well as culture-brand congruence.

- Customer knowledge management involves capturing distribution of information about customers.

- Marketing organisation concerns skills, structures and processes within the marketing function.

- Communications optimisation involves deeper understanding of customer groups, managing customers on a lifetime basis and a universal communication and planning framework.

This is illustrated in Figure 1.

The research showed that most brands consider that there is significant opportunity for them to improve in their performance, with 80 per cent or more rating their brand's performance and scores equivalent to mediocre or worse in each category. The competencies model is consistent with the management drivers model.

Thus, best practice in communications planning derives from a coherent organisational and brand identity, with the communication mix developed creatively and rigorously to optimise spend and performance across all brand-customer interactions. The research supports that of Schultz and Kitchen ${ }^{46}$ and shows considerable evidence of practitioner adoption and intention. COI, IBM, P\&G, Coca-Cola, Unilever, Nestle Rowntree, Masterfoods, National Trust and NSPCC, among others, have made decisive shifts in communications planning, as have agencies like MindShare, Euro RSCG, MediaEdge:CIA and Saatchi \& Saatchi.

The benefits of such an approach include:

- brand recognition and image enhancement; ${ }^{47}$

- increased loyalty, with consequent financial effects; ${ }^{48}$

- enhanced selection of media and disciplines (ie channels) with efficiencies in contact cost and reach, as well as increased communication effectiveness; ${ }^{49,50}$

- media-multiplier effects, which lead to enhancements in communication power through synergies between communication channels when they work in harmony; ${ }^{51-53}$ enhanced management of customers over time and across contact points; $; 4,55$

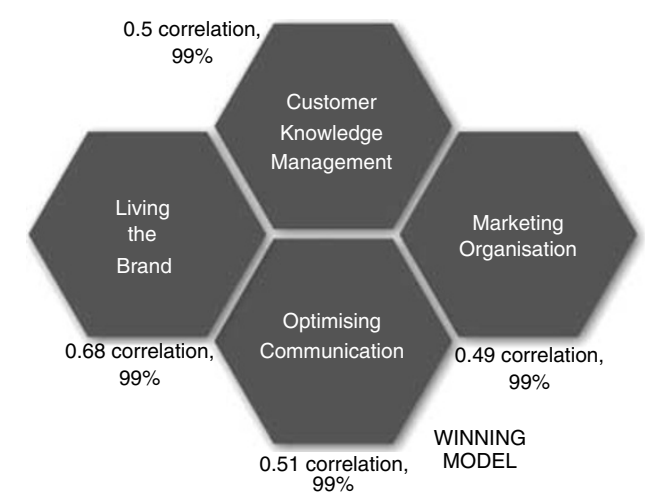

Figure 1: Winning with customers competencies model. Source: Jenkinson, A., Mathews, B. and Sain, B. (2005) 'How to win with customers, integrated marketing and its effectiveness', Centre for Integrated Marketing; available at: http://www.stepping-stones.org/Winning_with_Customers.htm 
- enhanced employee commitment and alignment, with consequences for organisational performance and customer/ donor experience, ${ }^{56,57}$

- reduced operational and marketing costs relative to effects. ${ }^{58,59}$

Consequently, for many senior marketers, the question is not whether to plan on an integrated and media neutral mixed-media, mixed-discipline basis, but how to do so. As the scope has increased to include not just integration and media-mix planning across advertising media but across all contact points, the scale of the challenge has become increasingly apparent. To be explicit, this means that it should be possible to plan and evaluate not just traditional marcoms activities like direct mail and television, but also include a store window, a merchandising rack, a salesperson's customer call, a press release or a product or stunt. Put simply, many marketers wonder how to do this, and if it is even possible. This paper suggests ideas, process and tools that appear to solve this dilemma, which unfortunately requires changes to existing norms.

The central consideration of the paper is the commonly practised allocation of different communication objectives, and therefore evaluation criteria, to the variously used communication methods and media. It is suggested that the current challenge arises systemically from a divisive approach to planning and evaluation, and that much of the difficulty disappears when a unified approach is adopted. It is further argued that the recommended changes enhance creative opportunities for all of the disciplines and their agencies, including direct marketers.

An analogy may illustrate the point. It is common to design a meal around different kinds of food, which also have different kinds of preparation. For example, a savoury or other starter, possibly a soup, a savoury main course with different ingredients (meat, vegetables) and a final sweet dessert. The inclusion of balanced variety is celebrated as an art. It is clearly appropriate to regard the dessert and the main course as having different roles within the meal.
At the same time, both can also be considered on precisely the same criteria. Their functional performance in nutrition and excellence of enjoyment are common factors. It is possible to have a dessert that is high in protein and/or vitamins (nuts and fruit), and a main course that is high in carbohydrates and sugar (white rice, potatoes). It is possible to make any part of the meal the high point. There are restaurants where you save up for the cheese course or the dessert and others where the starters rule.

It is therefore appropriate to see each course as having a different role, but dubious to assume that there is no common ground for analysis or evaluation.

In the same way, and indeed more strongly, it seems possible to recognise individual characteristics within the communication tool box while also assessing them on a consistent set of planning and evaluation parameters. Grant, ${ }^{60}$ for example, assigns different qualities to media, such as storytelling, memetic or reality media, but not in a way that excludes their common capacity to sell or build relationships.

To test and demonstrate the plausibility and practicality of this concept, and to move the debate from whether to how, a communications planning tool called CODAR was developed by the author. The more profound context for this was the need to provide practical methods for implementation of organisation-wide integrated marketing in a context in which even traditional media planning was recognised to be inadequate. CODAR has been applied and evaluated by the Centre for Integrated Marketing with the Media Neutral Planning (MNP) Best Practice Group (described below) and a number of clients and agencies.

\section{METHODOLOGY}

In addition to a literature review of academic and practitioner publications and practitioner databases, such as the IPA Effectiveness Awards, the paper is informed by original case studybased qualitative and analytical research into over 
30 brands with more than 80 in-depth interviews, mostly in the UK, with senior marketers from a variety of industries and disciplines, along with senior academics and representatives from professional bodies such as the Chartered Institute of Marketing (CIM), Institute of Direct Marketing (IDM) and Design \& Art Direction (D\&AD). A range of qualitative and quantitative investigative methods were deployed, including in-depth interviews, focus groups, action research, action learning, appreciative enquiry, participative discussion techniques, questionnaires, tools development and testing.

A 15-month CIM-sponsored judgment-panel research project into media neutral and integrated communication planning is another source. Its findings were endorsed and reported by the CIM in January, 2004 as a set of the recommendations and practices (methods) known as Open Planning (www.shapetheagenda.com), and also by the IDM (21st October, 2004) and the Centre for Integrated Marketing. The project involved more than 20 senior marketers (MNP Best Practice Group) operating across charitable, business-to-business, fast-moving consumer goods (FMCG), consumer durables and consumer services sectors. Members belonged to both brand and agency sectors, with agency representatives from public relations, advertising, direct media planning and other disciplines. Research methods included discussions, a web-based forum, expert witness statements, presentations, workshop activities and evidence/experience citation. New concepts and tools were also developed and trialled by participants. All meetings were recorded and transcribed, as information recalled from memory is imprecise and often likely to be incorrect. ${ }^{61}$ This resulted in a set of recommendations that constitute a comprehensive approach to planning known as 'Open Planning, ${ }^{62}$

Finally, the paper draws on a telephone survey of 200 senior marketers from UK brands and agencies designed to identify or confirm key factors in customer experience and brand performance. ${ }^{63}$ Each interviewee answered almost 30 questions in a 20-25-minute interview by a trained researcher.

\section{A HISTORY OF DIVISION, AND NEW METHODS}

It is a characteristic of the development of human knowledge to generate specialisation, which may lead to fragmentation of understanding. Jenkinson and Sain report on the history of communication thinking in the context of AOL. ${ }^{64}$ Historically, practitioners were much more likely to mix their methods, sometimes artlessly. Thus, the differentiation between brand and direct advertising was not a divisive factor. There is considerable evidence that, by the 1990s and into the 21st century, practitioners were inclined to put each of the methods into an individual silo, which is likely to be briefed and evaluated on separate bases, characterised by the ubiquitous use of the terms above and below the line. Furthermore, there are often strongly divisive characteristics in the brand organisation, such as the separation of responsibility for public relations and advertising agencies and the division of communication and promotion budgets between marketing and sales. Consequently, it is difficult in most organisations to manage a complete 'marketing' budget and even more difficult to decide on how to use it in an optimal way.

This is even enshrined in some marketing theory. A brief discussion of typical issues follows. ${ }^{65}$

\section{Media}

Lloyd cites 53 advertising media, ranging from cows with billboards to the floors of supermarkets, in addition to the five traditional media 'channels': network and cable television, radio, public relations, print and outdoor, and the internet, but excludes mail, e-mail and telephone, as they are not considered to be advertising media. ${ }^{66}$ By contrast, there is now a broad consensus among those interviewed that this form of discrimination or differentiation has little utility. The communication challenge is to consider all contact points with customers, and thus every channel of communication is a medium, including reality media such as the product, shop or service person. This, therefore, constitutes the media planning challenge, and by 2004 all leading UK-operational media agencies, 
including, for example, MindShare, Zenith Optimedia and MediaEdge:CIA, were already providing or seeking to provide services based on this concept. Given the move towards integrated marketing, the longer-term challenge for marketers is how to plan and execute in ways that include all of the brand's internal and reality media. For anyone finding it difficult to plan effectively across direct mail and television, this larger problem must look horrendous.

\section{Disciplines}

As for media, so with disciplines: the addition of a telephone number or a URL to an advert is considered to be enough to change its discipline. Many actual communication examples were tested as part of this study, and were discussed with practitioners, gaining wide agreement that neat segmentations did not correspond with reality. Rather, the best work is a fusion. Young people standing outside St Pancras station handing out www.thetrainline.com cards announcing the availability of a new web booking service are creating 'awareness', considered to be an advertising activity, and precisely mimic medieval street criers, whose activities are the etymological origin for the term. They were probably 'bought' as 'promotions', however, and of course they are trying to create 'drive to web' response.

Furthermore, the most powerful communication is frequently obtained by means outside the 'marcoms' methods. When Virgin hand out ice cream with their in-flight movie, what is this? When Apple designed iMac to look so stunningly different, or Costa Coffee spent their television ad money on cafe redesign, or BHS and Tesco spent marketing budget on new shop staff, these were product/service/communications design fusions that worked like advertising, direct response and public relations stunts. What type of communication is a row of 20 Chrysler Cruisers lined up down a busy Northampton pedestrianonly street by a sponsored owners' club? Budweiser and Marmite's advertising transformed their products, as well as acting as a powerful public relations tool. ${ }^{67}$ SEEBOARD Energy spent their human resources budget on television advertising. ${ }^{6}{ }^{6}$

Instead of being stuck in discipline silos, it appears more effective to define communication objectives in ways that enable each skill group to contribute. This creates a new conceptual platform for planning: moving to the primacy of the idea followed by the best way of executing it, without recourse to artificial boundaries, is increasingly seen as a more effective route. Saatchi $\&$ Saatchi are seeking to rebrand themselves as an ideas agency, and several major marketing firms now label all of their agencies as just 'communications agencies'. There are obviously practical skills and enduring intrinsic qualities associated with the various media and disciplines, and with teams of people. After all, there are things you need to know to make a television ad or a mail pack, and practical differences between their communication dynamics and qualities. At the same time, the research observed an advertising agency writing copy for product packaging for the sales promotion agency, which was developing branding concepts for advertising (Masterfoods brand). At the NSPCC, ideas can come from any agency. ${ }^{69}$ There was consensus among the Best Practice Group that less restrictive ways of thinking about media and disciplines is therefore necessary. This would imply that while there is a continuing need for specialised agencies and teams, thinking about what they do needs to be liberated. In many circles, this is no longer a question; rather, the challenge is how to plan, execute and evaluate more effectively in this new world.

\section{Evaluation criteria}

Evaluation is a further major issue. Agencies survive profitably when clients evaluate that their performance is excellent. Equally, brands require accurate evaluation in order to be able to do good work and therefore prosper. Any successful means of evaluation would therefore meet a variety of objectives. It must contribute to learning by all of the parties. It must be seen as fair. It must reflect realities rather than prejudices. It is widely noted that current methods often fail 
on one or more of these counts. Specifically, they are often:

- too one-dimensional to give a rich perspective on performance;

- too different across the mix of methods to provide a common platform or currency; and

- too likely to be based on unspecific, inappropriate or inaccurate requirements to give effective feedback.

A respected view is that: 'TV is awareness, direct mail is for sale completion, door drops (trial), web-sites (info backup), and PR (credibility), and the solution is to find the appropriate mix'. ${ }^{70}$ Gerin asserted, 'exclusive use of attitude media is no longer sufficient .... We must consider ... behaviour media' (authors italics). ${ }^{71}$ Such demarcation assigns single-value benefits to the various options, and these single-value contributions become the basis of monotelic (ie single-goaled) planning and evaluation. Given the more complex and rich view of media and disciplines indicated above, there seems to be an intuitive case for suggesting that this is inefficient.

Traditional evaluations are another hurdle, as exemplified by Tina Kaye, "We are ... influenced, either overtly or subconsciously, by the knowledge of how our campaigns will ultimately be evaluated ... according to ISBA [in 2001] 45 per cent of pay by results schemes use advertising awareness as their basis of assessing performance'. ${ }^{72}$

The research cited above discovered that it was common practice to employ qualitative techniques for the evaluation of television advertising, but this was rarely used, even when budgets were equivalent in size, for direct marketing/mail. Direct marketing is measured by response because it is easy, improves performance and reflects marketer's needs. This narrow focus probably derives from the competitive advantage direct marketing gained over advertising from 'accountability', however, which led practitioners to promote this 'hard' but narrow capability, which was not part of earlier thinking. ${ }^{73}$ Because direct marketing and sales promotion are rarely tested for brand image effects, marketers have excluded broader learning, and therefore paradoxically real accountability, but there is little doubt of the wider potential for communication effects. ${ }^{74}$ Obviously, many practitioners and thinkers have argued and demonstrated that direct marketing can and does affect brand and customer relationships; indeed, relationship marketing is a basic of direct marketing. As long as performance is measured on one factor alone, however, this is likely to distort the creative brief and execution. IBM, British Gas and Sainsbury cited their own practice of measuring only direct marketing response, all agreeing that changes were necessary.

A further heuristic side effect is the tendency towards laziness in defining communication objectives. For example, many advertisers pursue awareness and ad recall because these are the easiest way to measure ads. A media agency presentation at a Marketing Week conference (July 2003) of a Levi Strauss pan-European campaign cited ad awareness achievements. Private discussion with the European CMO confirmed that ad awareness was definitely not the objective: consumers' beliefs are what matter. To this can be added, feelings: Millward Brown's BRANDZ studies of thousands of brands worldwide show that brands have very different profiles in the development of customers, from brand presence (awareness) through higher levels of relationship towards 'bonding', which is typically six times more powerful (source: BRANDZ database). The evidence is that awareness is weakly correlated with success. Furthermore, as a complement to direct marketing's over-exclusive focus on response, advertising is often not tested rigorously for sales effects.

Thus, both 'advertising' and 'direct marketing' (to cite but two examples) are frequently executed with limited recognition of their full potential.

Indeed, the real potential can be so large that results actually invert assumptions. Boots found that mail media generated 27 per cent more recall at 64 per cent of television cost when launching a new Boots No. 7 product to the target audience. ${ }^{75}$ Volkswagen found that television advertising drove visits to showrooms and sales. ${ }^{76}$ 
Observation of actual practice also demonstrates that it is commonplace for there to be a radical difference between the communication objectives given by the client, and used for evaluation/ measurement, and those actually embedded into the executed communication. Examples can be found in major FMCG, retailer, business-tobusiness and financial services brands. When a more sophisticated planning tool is applied to the client brief and again to the signed-off work, there are very distinct differences (see Figure 2). This is interpreted as indicating that the creative director understands that in order to achieve what the client wants, they are unable to do what the client is asking for. For example, a client may drive for activation and behavioural response, but the creative/agency understands the need to create experience and emotional rapport as a means towards a business goal. It could be argued that such a difference has always been enshrined in the relationship between client and agency and that it is the ability of the agency to add such value that contributes to their value.

Alternatively, the marketing director may wish to have his or her team take more care over communication objectives and thus learn what communication effects (and affects) actually drive business goals. Many client briefs seem to confuse business objectives with communication objectives.

\section{Structure, language and tools}

Divisive organisational structures are widely noted. 'Most marketing departments are still structured in a way that doesn't align with the world they are trying to address: ... consumers don't exist in media specific silos'. 77 'The fragmentation of agencies into discrete specialisations means that everyone has a vested interest in promoting their discipline at the expense of others' ${ }^{78}$ The silos of discipline-specific teams are still common practice within both clients' marketing departments and
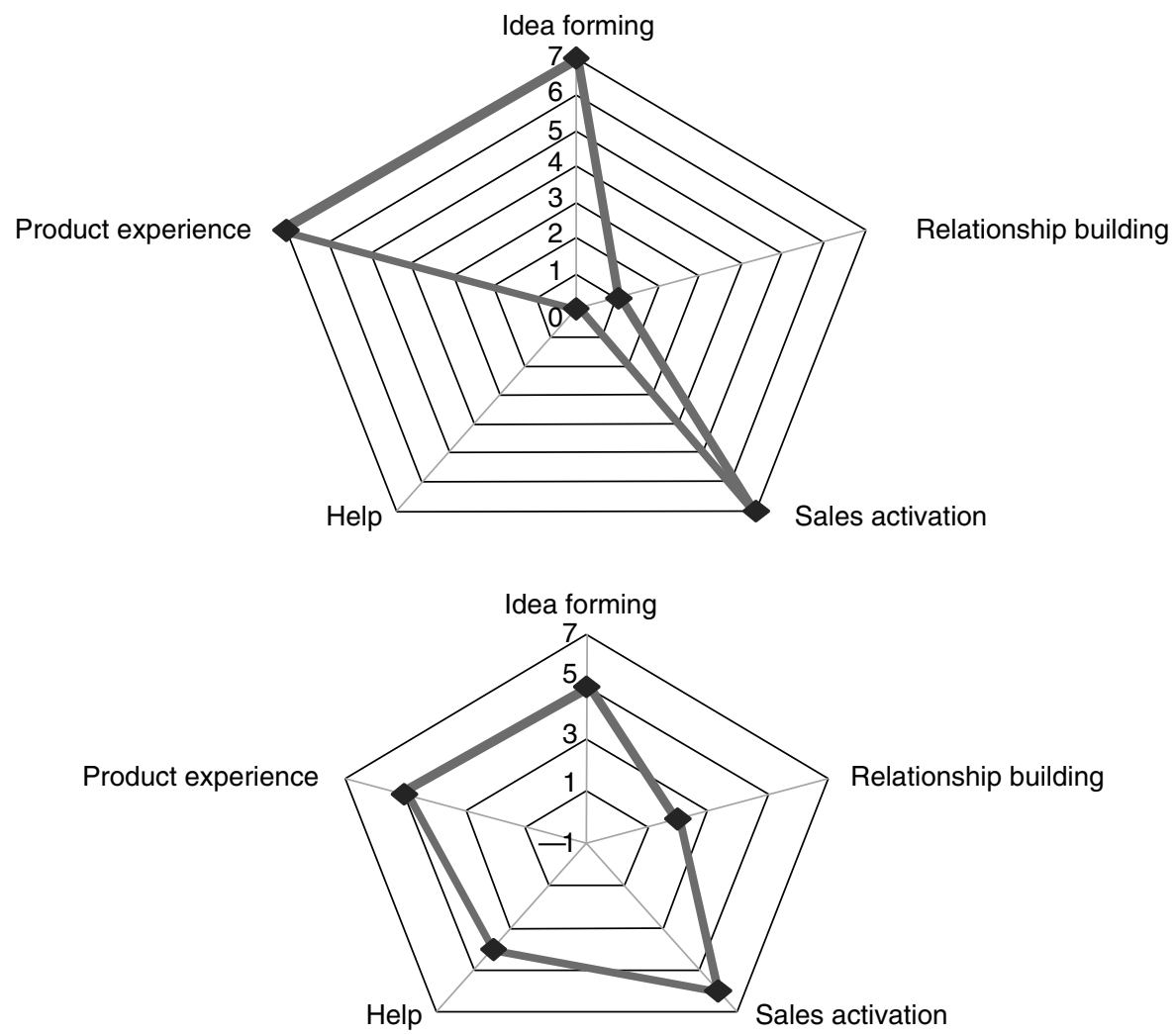

Figure 2: There is a radical difference between client objectives (brief, top) and approved execution (bottom), which shows up when a precise planning instrument is used (illustration uses the CODAR tool, major FMCG brand and direct mail pack) 
multi-discipline agencies. According to Dawson and Ellyatt ${ }^{79}$, 'Agency business models remain based on execution while client structures generally reinforce a "silo" approach to the communications channels available'.

There is now a broad consensus among leaders and thinkers in the field, which may not always correspond to brand behaviour, that all marcoms can and should positively affect both brand equity and sales, although the precise mix of achievement would normally vary over time. This implies the need for learning and involvement between disciplines, as well as common methods for defining and measuring, sometimes referred to as a common currency.

It is also broadly agreed that communication needs the right mix of media and disciplines in order to optimise results, and that therefore the agencies/skill groups need to work as a team. This creates new planning and process requirements: the business and communication challenge must now be shared with a team of agencies/skill teams to get a variety of perspectives and ideas driving towards a shared solution. There is a need for common language and instruments. Observation of planning sessions between agencies noted how practitioners use the same word to mean different things and different words to mean the same thing. Furthermore, some concepts do not have a name while others suffer from a plethora. One of the basics in quality management is the concept of an operational definition, which is a description of quality or performance that enables one to know whether or not it has been achieved. Such functional precision about communication tasks would be useful in the marketing community. Thus, the open planning group arrived at media (anything that conveys a message), discipline (means of using the media) and channel (the mix of the two) as simple and precise terms. Rather than referring to above the line, it would be more useful to refer to, say, attitude generation.

Furthermore, communication objectives need to be described in terms that work equally well for all types of communication.

Jenkinson et al. ${ }^{80}$ identified six operational competencies that drive 50 per cent of customer experience and integrated marketing performance across some 200 UK brands. One of these is the use of a universal communication planning method. As discussed below, the application of such a method appears to overcome many of the cited issues. Absence of universal standards held back numerous industries, including transport, information technology and electrical. Arguably, current dysfunctions in approach to the different marketing communication methods are equivalent to those in the electrical industry before Institute of Electrical and Electronics Engineers, Inc. standards or the computing industry before World Wide Web protocols.

\section{Summary}

In summary, the marketing communications industry is achieving excellent results in its parts. But it reflects decades of gradually increasing fragmentation and competitive practice, habit and payment methods, which many are now seeking to change. The consequences include some mental and organisational structures that suboptimise performance and polarise practitioners' views. It is widely agreed that changes are needed to concepts, skills and tools to meet the contemporary challenge. New methods have been developed, however, although many remain ignorant. Research by the Best Practice Group concluded that most companies can enhance their marketing performance by at least 10 per cent, and sometimes up to 25 per cent. Integration does not mean making a jigsaw out of pieces, especially if they do not fit. Rather, integration means taking a unifying, media and discipline-neutral organising idea and articulating it across a creative and rigorously analysed mix of media and methods in such a way that every group can contribute and be evaluated effectively. Every piece of the jigsaw needs to reflect the whole idea.

\section{OPEN PLANNING: A UNIVERSAL METHOD}

The MNP Best Practice Group identified a new planning framework consisting of concepts, processes and tools for both integration and media neutrality, with elements as shown in 
Figure $3 .^{81}$ The ten elements were characterised as follows:

1. Effective planning requires unprejudiced and therefore open thinking.

2. Its goal is to create customers who are open to buy; they have open wallets.

3. It assumes that all disciplines are inherently capable of working with all media and of achieving a full range of fundamental communication objectives; consequently, they are open disciplines. Furthermore, disciplines can be blended or fused in any communication execution.

4. It assumes that anything that conveys a message is a medium, and following (3) above, that any medium is open to any and all disciplines in any mix.

5. The term 'channel' denotes a particular fusion of medium and disciplines. The planning process should take in an unprejudiced, rigorous and creative approach ('open') to selecting the right mix of channels.

6. The group provided a template for a recommended planning process (see www. openplanning.org and Figure 4) that is designed to be clear in requirements, open to ideas and rigorous in defining the right solution. It has four process meta-elements (each includes a number of specific process actions): (1) identifying the business issues/ challenges for the brand in relationship to specific customer groups; customer insights; (2) identifying the communication challenge with provisional insights about disciplines and media; issuing of a single, open (ie media and discipline-neutral) 'master communication brief' to all agencies; provisional development of the unifying creative idea; (3) detailed

\begin{tabular}{|c|c|c|c|}
\hline 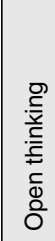 & 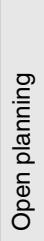 & $\begin{array}{l}\text { Open disciplines } \\
\text { Open media } \\
\text { Open channels } \\
\text { Open process } \\
\text { Open structure } \\
\text { Open relationships } \\
\text { Open results } \\
\text { Open tools }\end{array}$ & 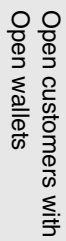 \\
\hline
\end{tabular}

Figure 3: Open planning framework development of a solution based on articulating and executing a unifying creative idea across an efficient and effective media and disciplinemix as a collaborative process between creative insights/ideas and media dynamics (costs, reach, match to desired segment or community, characteristics, etc) and (4) a continuous learning process. See also the specification of operational principles below.

7. The organisation structure, including policies, processes and budgets that shape the planning system, should be restructured in specific recommended ways to remove blocks to the most effective solution mix. One recommendation is to move from a media/ discipline organisation to a customer segment structure.

8. The group recommends a set of principles for relationships between the client and the agency team, including intra-agency relationships. These include removing any hierarchy between the agencies, primacy coming from good ideas not the agency discipline.

9. The combination of rigorous systems and unprejudiced thinking should lead to more effective results analysis across the full spectrum of communication activities, using a common currency. This is discussed in more detail below. The group also recommends an element of payment by results, with each agency being paid in part on collective results (ie teamwork), independent of the actual work done by each agency on a particular project.

10. Finally, to make this work, the group recommends the adoption of 'open tools', including methods or systems, such as the 'open process', which facilitate practice, embedding the principles into activities. The CODAR tool, which is designed to facilitate all ten of these recommendations, was indicated as one useful example and will be discussed in more detail below.

The Open Planning process is therefore based on four sets of operational principles:

1. Business-driven insights: Identify the stakeholder community segment for communication and 


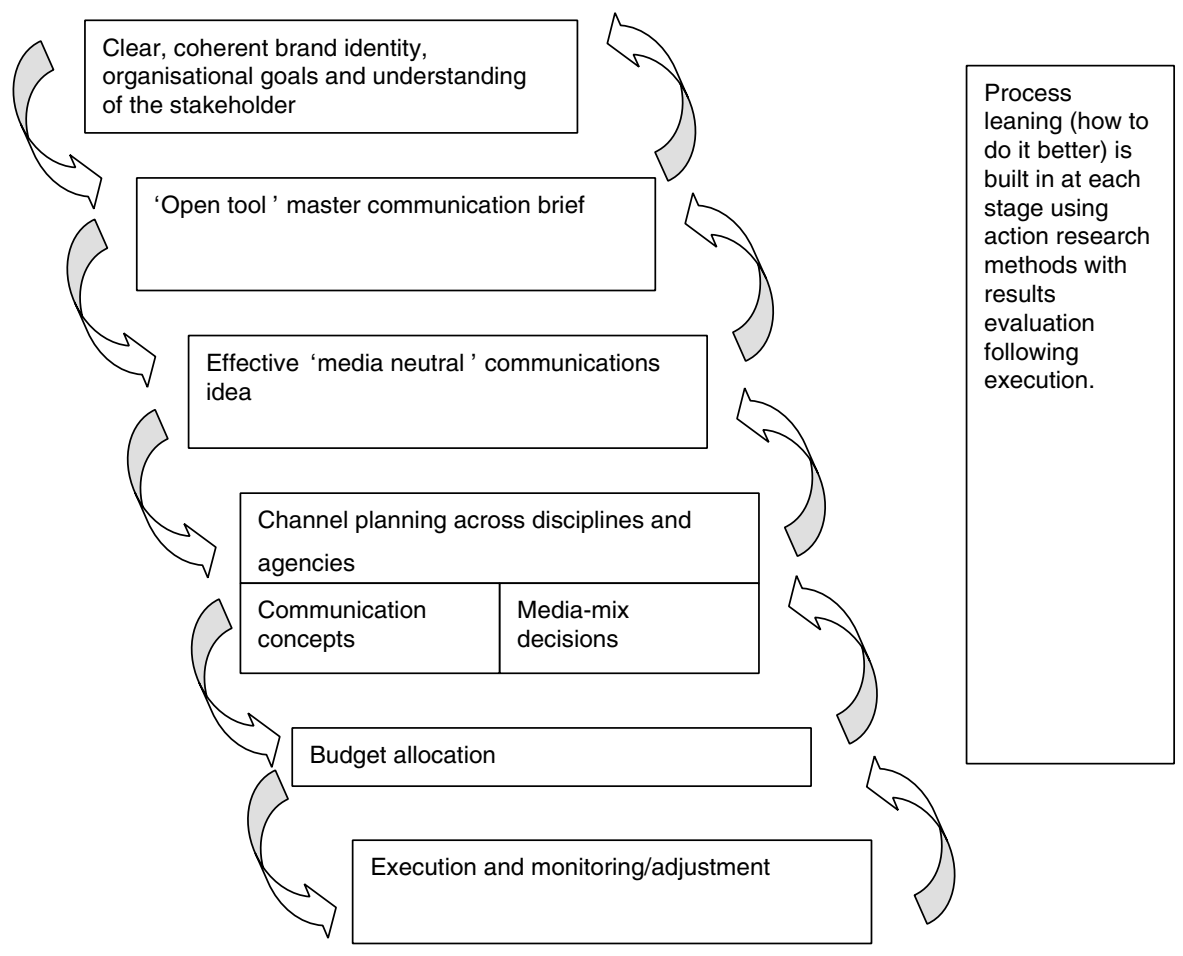

Figure 4: Open process steps

the business and communication challenge; business goals and customer insights need to drive the process. This also means that there is a clear differentiation between the business objectives and the communication objectives. Communication objectives are intended changes in the customer/prospect that contribute to short-and/or long-term business goals.

2. Universal fractal planning: Plan communication goals from the highest strategic levels of brand positioning to the fine detail of a banner, mail-pack insert or phone script using a single, standard planning and evaluation framework. This framework needs to be based on fundamentals of the human being. ('Fractal' is a term coined by the Nobel Prize winning scientist Mandelbrot to refer to structures that replicate, to increasing levels of detail, the whole reappearing in the parts, a phenomenon common in nature and key to chaos theory.) All forms of communication end up in the mind of the consumer and in the consequent actions that they take. The communication framework needs to reflect these universals; for example, all communication changes the way people think.

3. $360^{\circ}$ optimisation: Plan, optimise and brief across anything/all that communicates: charity shop, mail-order product, television, mail, sponsorship, public relations, etc, treating each genuinely on its merits in a way that stimulates maximum creativity (every contact point represents a medium) and with agencies working as a team. Recognise that any communications discipline or medium can potentially achieve any type of communications objective; that the effect of media and disciplines wear out with excessive use and that sufficient force is needed to create an effect.

4. Common currency evaluation: Post-execution, evaluate communication and business effectiveness and efficiency using common currencies, based on the common framework. Specifically, the structure of evaluation should contain three elements: attainment of shared business goals (such as market share or sales volume, attainment of which should be a shared factor in team payment, thus promoting 
a partnership in results); the attainment of universal communication goals (such as feelings of relationship or beliefs) and the discipline or media-specific metrics that show attainment of these communication goals, which allows for the special dynamics of each communication activity.

\section{PRINCIPLES FOR AN OPEN PLANNING TOOL}

In this section, the CODAR system will be discussed. CODAR ${ }^{\circledR}$ is a proprietary tool: individuals and organisations should be trained and licensed to use it. It is not the only tool that conforms, at least in part, to open planning principles. For example, Integration MCA is a research agency that has developed a methodology for assessing the efficacy of contact points for brands and categories; it assesses all contact points using a common framework with proven results. MindShare has developed media planning instruments that describe media on a variety of dimensions, which can be customised for individual brands, the results being used in media optimisation analysis. As indicated above, however, part of the rationale in developing CODAR was to prove the practicality of media-neutral, integrated communication planning and evaluation, so its principles are defined in its international patent application. Furthermore, the CODAR tool was designed as a communication planning and evaluation instrument rather than a media optimisation tool.

The NMP Best Practice Group specified six Open Tool principles:

1. A good open tool operationalises best practice concepts. It is practical and easy to use, flexing from 'back-of-the-fag-packet, meeting-in-acorridor' discussions to econometric analysis and software process tools.

2. It should support the entire cycle from initial research through to final evaluation in an integrated framework.

3. It should be people oriented, rather than media/ discipline oriented; indeed, it should be based on fundamental insights into human beings and communication.
4. Communication objectives should be independent of the specifics of media, disciplines and channels that will (eventually) be used, while also facilitating definition and evaluation of individual choices: a single instrument for all agencies and all communication activity, from macro to micro detail across all contact points; thus, it should work seamlessly across all elements of the communication mix.

5. It should be rigorous in specifying communication insights/objectives, as indicated above, so that they are both creative and evaluation friendly. It should facilitate better briefs for creatives, media planners and analysts, with no trade-off between them.

6. Facilitating learning as much as analysis, it should develop both soft and hard knowledge and facilitate progress or evolutionary learning from continued use. Thus, an ideal tool will improve quantitative accountability and econometric modelling, while at the same time supporting learning about how and why elements of the communication mix worked.

\section{MECHANICS OF OPERATION}

The CODAR system deploys a framework of five dynamic and interdependent planning dimensions, which form the 'signature' for any communication. The dimensions are based on human psychology, marketing communication and planning/ evaluation needs. It is proposed that the same five dimensions are used for any and every communication, from master level campaign or project to web banner. The planning process assumes that preliminary research/analysis (at some level of detail) will arrive at insights for each of the five dimensions, which will be translated into communication objectives and priorities.

CODAR's five dimensions are organised in a circle reflecting a dynamic interdependence and enabling the use of a radar chart for planning and reporting purposes. Three of the dimensions relate to the classic cognitive, affective and conative (think, feel, will/do) elements of attitude, which have almost a century-long history within marketing, education and psychology. The 
CODAR model avoids serial communication models, however, such as hierarchy of effects, ${ }^{82}$ AIDA $^{83}$ and 'information sequence'. ${ }^{84}$ But all five dimensions draw from a wide range of sources. For example, they refer to the importance of emotional relationships and experience, ${ }^{85-89}$ service and help, problem-solving and objection handling (eg cognitive, sales and service theories). ${ }^{90-92}$

1. Idea forming: Influencing ideas, associations and beliefs, for example, about the brand, company or product. This dimension also relates to positioning and proposition in communication planning. In research, it asks how the consumer/customer considers the brand and competitive brands (or other relevant offerings) and what beliefs are necessary to achieve the desired level of change. This objective is classically aligned with advertising strategies and brand positioning, as well as concepts such as unique selling proposition. The Centre for Integrated Marketing has, however, noted this as a component of every form of marketing communication, from new product development to product packaging, personal selling to public relations, including internal marketing.

2. Building relationship feeling: Creating emotional connection. The objective is a feeling of being practically connected with the brand (or business proposal). Examples might be feeling affinity with the values of the brand or culture, feelings of trust and appreciation, feeling valued through being personally recognised and appreciated, knowing representatives of the brand and valuing relationships with them, belonging to some privileged or special group, and involving the brand and its products more in everyday life. This dimension has been strongly adopted by relationship and service marketers, the sales force and account management, as well as by brand advertising.

3. Activation: The objective is to get an intentional or behavioural change; for example, sales activation, sales enquiry or a commitment to behaviour change. This attitude leads to buyer and buy-in behaviours, and is therefore strongly present in most marketing and sales strategies, including internal marketing, while finding a strong home in direct marketing and sales promotion.

4. Help: The objective is to provide required and perceived help, service or support, for example, in the form of information about a product or policy, or help in a process. Here, the aim is to reduce anxiety and generate a sense of being cared for, being at ease, trusting, which is a driver of relationship and loyalty. 'Help' links to service marketing and is influential in developing attitudes, including ideas, relationship and activation, and of course for many brands it is a driver of positive product experience measured by satisfaction studies.

5. Product, service or environment experience: The objective is to give the recipient an experience, whether actual, such as in a product trial, or imaginary, such as through a virtual, visual or verbal representation of the subject or product that stimulates a rich imaginative experience. This is a commonplace of both brand advertising and personal and direct selling, as well as product packaging. Given that customers are less likely to buy something they cannot imagine or have not experienced, this is considered an important communication objective and a classic of sales promotion, service and product strategies, again often measured by satisfaction. Thus, total quality management, lean and value engineering in new product/service development management are focused on developing the customer experience dimension, while HR focus on employee experience.

These theories are detailed in Figure 5.

It is argued that each of these is present to some extent in every act of business-oriented communication. Papers by the Centre for Integrated Marketing give a number of examples. ${ }^{93-97}$ They show that, in principle, CODAR can be used to plan, brief and evaluate a wide variety of communication, at any level, and to brief any agency or business partner, including internal functions and people. The relative priority and specific objectives of each element, however, will vary from communication 


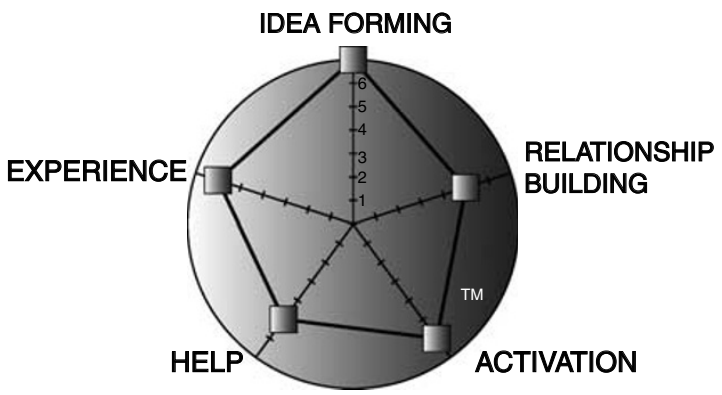

Figure 5: CODAR signature dimensions

to communication. Deciding on the relative priorities (represented, for example, on a radar chart) and specific content of these objectives and subsequent performance evaluation metrics constitutes the planning challenge. As ever, creative minds take these priorities and objectives and translate them into successful ideas and executions, sometimes in a single image or phrase (eg 'Never knowingly undersold').

CODAR therefore follows the open tool principles described above. The method for using it can be summarised in seven steps:

1. An overall business-related goal, such as market share, brand or customer equity.

2. A hierarchical but fractal communication planning structure: master communication objectives (in a master communication brief) with multilevel subsidiary communication objectives and activities (eg from global brand positioning to a banner ad; see Figure 6).

3. Communication priorities and objectives are specified for each communication activity, from master plan to the lowest level communication activity, using the same five dimensions. It is assumed that this is informed by research; the research agency could, for example, receive a brief that asks for insights across the five dimensions. Priorities and objectives are specified for each discrete community, so each has its own master level CODAR chart and communication plan.

- Priorities (ie the relative importance of each dimension for this communication activity) are expressed numerically (typically on a scale of 1-7), which can be shown visually on a radar chart (see Figure 5; the particular shape of the radar charted priorities is known as a CODAR signature). The CODAR system imposes restrictions on the total number of priority points that can be allocated across the five dimensions to force prioritisation. Users can also customise this. The WRC case ${ }^{98}$ shows how relative priorities change over the first, second and third years, as shown on a radar chart.

- The communication objectives are also specified as precise statements (ie semantically), a key task for the account planner, which should be based on research insights. For example, a 2002-3 AA rebranding programme (from 'the 4th

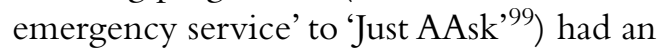
idea forming priority of 6 with the specific objective that motorists believe that 'the AA has a wide variety of relevant products besides roadside coverage'. More than one semantic objective is permitted, although users are encouraged to be parsimonious and focused. Where more than one objective is identified, the relative importance is indicated using percentages.

4. A set of practical numeric metrics for each planning dimension defines 100 per cent success. This means that it is possible to score achievement on each dimension. Plan versus actual can be reported with two lines on a radar chart and also reported as indexed scores. ${ }^{100}$ More than one metric is possible, each being weighted. An example of this (for the AA example cited) could be: a 40 per cent increase in number of AA products known to motorists ('awareness') and a 25 per cent increase in number of products considered relevant to motorists ('salience'), with the second element contributing 75 per cent of the total. This means that it is possible and practical to have communication-specific methods of evaluation that translate into universal communication objectives. A database holds this information, including the translator unit to facilitate econometric analysis.

5. A defined relationship between lower and higher-level communication activities, so that 


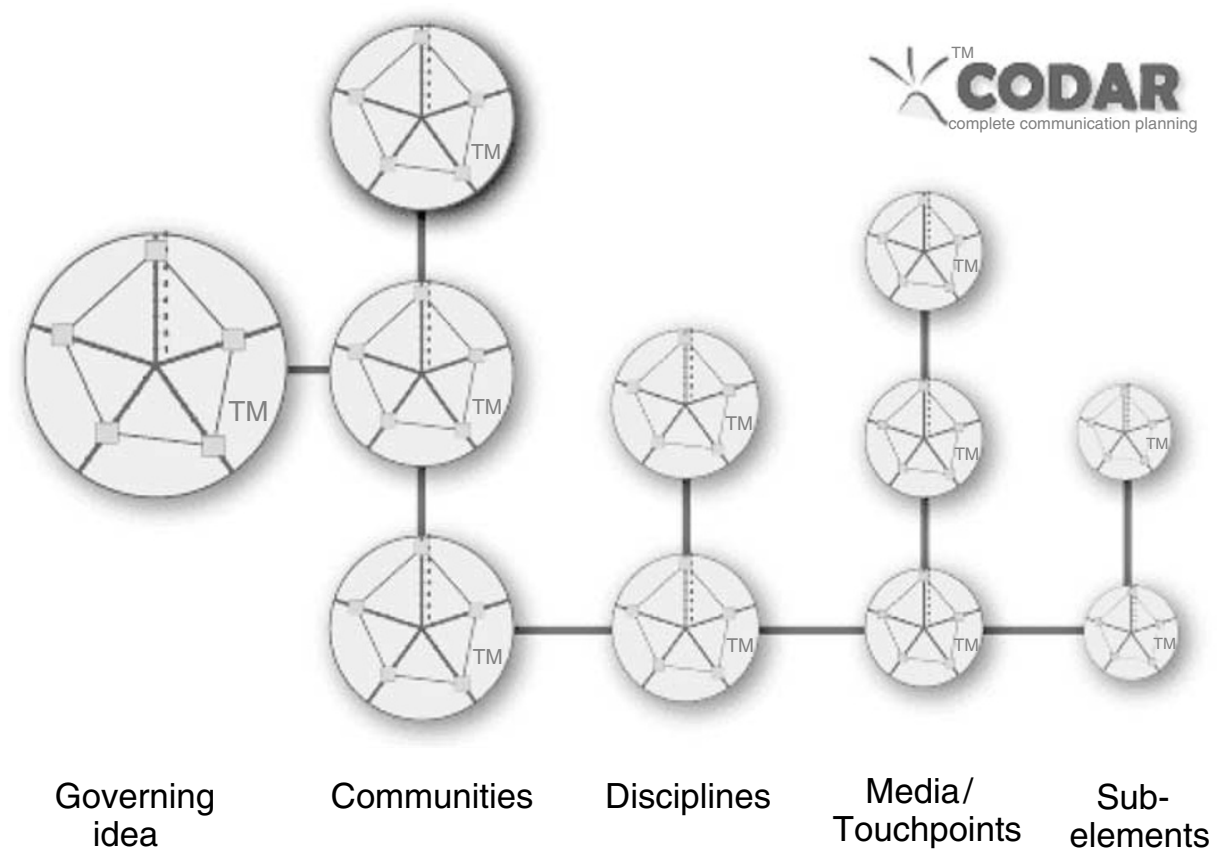

Figure 6: From master level to detail

the contribution of each communication activity to the overall plan is clear and can subsequently be automatically calculated. Examples include the planned contribution of a particular press ad in a particular newspaper (on a particular day). Both over- and underperformance are meaningful and contribution can be normalised against budget.

6. It is recommended that communication plans/ briefs are held in a database and are subsequently updated by actual performance (whether derived from research, estimates or CRM/ point of sale (POS) systems) triggering performance scores as indicated in point (5) above. Thus, the database can be used for econometric analysis and benchmarking, enabling comparison of different methods, markets, groups, products, media, etc. Whereas econometric analysis normally simply relates the amount of spend in a particular channel to the business result, use of CODAR enables functional analysis of the drivers of business performance on its five dimensions, enhancing skill. In this way, although CODAR assumes the neutrality of all media and disciplines as a starting point, it is possible to identify the performance profile of each channel as well as brand/category profiles and trends. Inevitably, this requires the collection of a body of data. Used either in conjunction with these hard data or by input from a knowledge panel, this can facilitate media optimisation. If the database is held internationally, then comparison can be international. Comparison can also be made across clients by an agency or consultancy and used for benchmarking or category analysis.

If all communication projects/briefs/cases are CODAR coded, then they can also form the basis of a knowledge management system and the CODAR signature becomes a useful access method for research by employees ("what work has been done in cosmetics that involved the CODAR signature 5-3-3-5-4?'). CODAR can also be applied retrospectively to existing cases to get a rapid start, and this can also serve as a useful training tool.

The CODAR tool is then built into the open planning process. For example, an initial discipline/media-neutral brief (master communication brief) would normally be issued, as indicated above and employed at the NSPCC, ${ }^{101}$ using the CODAR tool. Individual 
agencies respond, following discussion, with proposals reflected in a variety of CODAR signatures.

\section{Practice}

The open planning process has been adopted by a number of organisations, although it is not always clear who was using it or how successfully. WPP reported use of the method with Vodafone for UK and international communication planning, ${ }^{102}$ as did IBM.

CODAR is a relatively new tool, and it takes time to develop sophisticated databases and a wide body of use, particularly as the tool was not developed by a major organisation. Nevertheless, it has been applied or tested, as indicated by the case studies, to a variety of different categories and brands. The NSPCC uses CODAR to facilitate communication planning across a network of some ten internal and external agencies within the context of an open planning process. ${ }^{103}$ IBM have reported how CODAR helped them to plan communications to C-level Business Consulting contacts internationally. ${ }^{104,105}$

The integrated consulting agency, KB49, has used CODAR with some dozen brands, including Masterfoods and Abbey. Creative director Andy Blackford comments:

'CODAR is above all a lens - a means of focusing upon the real issues facing a brand and its communications. It provides a structure around which to create a hierarchy of priorities based on real customer issues. For example, by "rationing" the points that can be allotted to every set of objectives, CODAR acknowledges that we work in an imperfect world of scarce resources, where marketers are constantly faced with difficult choices. And yet, for all its compelling realism, it retains an elegant simplicity. This makes it especially attractive to practically-minded professionals like ourselves, who are not necessarily accustomed to working in the realm of abstract theoretical models. We find that establishing such formal parameters early in the process provides bold, imaginative work: once the structure is set then go mad creatively. We are also impressed by CODAR's versatility. It can be applied with equal facility at the planning, implementation and evaluation stages of a project. That project might be the launch of a new brand on a global scale or some small, discrete area of local activity'.

\section{CONCLUSION}

This paper has argued from evidence that there is a widespread recognition of the need for change in the methods of communication planning and that there is an associated quest for how to do so effectively. Based on research with a number of practitioners, it has indicated a number of principles that are seen to be useful and successful. It also outlined a specific communication planning tool that employs these principles to demonstrate the practicality of the ideal.

This recommendation would lead to a number of changes in practice and paradigm, changes already operational in a limited but increasing number of brands and agencies. These changes would involve replacing disparate planning and evaluation criteria with a unified model across all communication methods. Instead of different and discrete communication objectives and evaluation criteria, planners flex the same tool. It has been shown from a variety of categories and applications that this appears to be entirely practical.

In a single paper, it has not been possible to cover all the possible objections or questions. Nor at this point has it been possible to fully test every conceivable requirement, not least because insufficient time has elapsed to develop full-scale databases. There are thus significant opportunities for further research, practice and debate into both the general principles and the best methods of implementing them, opportunities which should contribute to the advancement of the open planning discipline.

As far as direct marketers are concerned, it is suggested that these suggestions should be welcomed as they provide a level playing field and richer options for practitioners and their agencies, proven opportunities to improve planning and evaluation with an enhanced experience for customers. 


\section{References}

1 Gerstner Jr., L. V. (2002) 'Who Says the Elephant Can't Dance?', HarperCollins Publishers, London.

2 Duncan, T. (2002) 'IMC: Using Advertising and Promotion to Build Brands', International edn, The McGraw-Hill Companies, Inc., New York, NY.

3 Jenkinson, A. (2000) 'Leadership creates loyalty', Journal of Database Marketing, Vol. 7, No. 4, pp. 342-355.

4 Acheson, K. L. (1993) 'Integrated marketing must bring two perspectives together', Marketing News, Vol. 27, No. 17, p. 4.

5 IPA (2002) 'VW "beautifully crafted", launching the facelifted Passat in 2001'. IPA Effectiveness Awards. Available to IPA members on http://www.ipa.co.uk/awards/databank.cfmor via WARC at http://www.warc.com/Search/WordSearch/ WordSearch.asp.

6 Berry, M. (1998) 'The New Integrated Direct Marketing', Gower, Aldershot.

7 Schultz, D. E. and Kitchen, P. J. (2000) 'Communicating Globally: An Integrated Marketing Approach', Macmillan Press, London.

8 Smith, P. R. and Taylor, J. (2002) 'Marketing Communications, An Integrated Approach', 3rd edn, Kogan Page, London.

9 Jenkinson, A. and Sain, B. (2005a) 'AOL: Redefining marcoms' in PMA Educational Foundation (eds) 'ROI of Integrated Marketing', PMA Educational Foundation, New York, NY.

10 Billet, J. (2002) 'Hard-edged Consumer Issues and Hard-nosed Media Solutions', CIM Publications, Maidenhead.

11 Jenkinson, A. and Sain, B. (2004a) 'Open planning, media neutral planning made practical', MNP Best Practice Group/Centre for Integrated Marketing/CIM; available at: http://www. openplanning.org/index.php?pgId=25(accessed 25th October, 2005).

12 Billet (2002). op. cit.

13 Smith, P. R. and Taylor, J. (2002) 'Marketing Communications: An Integrated Approach', 3rd edn, Kogan Page, London.

14 Billet (2002). op. cit.

15 Jenkinson and Sain (2004a). op. cit.

16 Jenkinson, A. (1988) 'Cross-selling personal financial services', Institute for International Research, London, and Jenkinson, A. (1989) 'Best practice direct marketing in Europe', Paper presented at DMA Annual Conference and Exhibition, October, USA.

17 Schwartz, M. (2001) 'IBM adopts new agency model', B to B, Vol. 86, No. 16, p. 21.

18 Tedlow, R. S. (1990) 'New and Improved: The Story of Mass Marketing in America', Basic Books, New York, NY.

19 Hampton, F. and Sawn, D. (2003) 'Identifying and applying appropriate measurement metrics to evaluate the success of integrated campaigns', Paper presented at Marketing Week Conference, London, July.

20 Eagle, L. C. and Kitchen, P. J. (2000) 'IMC, brand communications, and corporate cultures: Client/advertising agency coordination and cohesion', European Journal of Marketing, Vol. 34, No. 5/6, pp. 667-686.

21 Billet (2002). op. cit.

22 Neill, M. L. and Regan, T. (2004) 'Evaluation', in Saunders, J. (ed.), 'The Communications Challenge, A Practical Guide to Media Neutral Planning', Chapter 5, The Account Planning Group, UK, pp. 111-144.

23 Jenkinson, A. and Sain, B. (2004b) 'Advances in communications optimisation for CRM and IMC', Paper presented at Corporate and Marketing Communications Conference, Warwick Business School, University of Warwick, 5-6 April.
24 Jenkinson and Sain (2004a). op. cit.

25 Jenkinson and Sain (2004b). op. cit.

26 Christopher, M., Payne, A. and Ballantyne, D. (1991)

'Relationship Marketing', Butterworth Heinemann, Oxford.

27 Jenkinson (1988). op. cit.

28 Jenkinson, A. (1995) 'Valuing Your Customers', McGraw Hill, Maidenhead, pp. 44-58.

29 Kitchen, P. J. and Schultz, D. E. (1999) 'A multi-country comparison of the drive for IMC', Journal of Advertising Research, Vol. 39, No. 1, pp. 21-38.

30 McGoon, C. (1999) 'Cutting-edge companies use integrated marketing communication', Communication World, Vol. 16, No. 1, pp. 15-19.

31 Woodcock, N., Stone, M. and Foss, B. (2003) 'The Customer Management Scorecard: Managing CRM for Profit', Kogan Page, London and Sterling, VA.

32 Gonring, M. P. (1994) 'Putting integrated marketing communications to work today', Public Relations Quarterly, Vol. 39, No. 3, p. 45.

33 Jenkinson, A. (1996) 'The laws of loyalty marketing: An intensive review', Journal of Database Marketing, Vol. 4, No. 2, pp. $146-167$.

34 Reich, K. (2001) 'Some things still work don't they?' Communication World, Vol. 18, No. 3, pp. 26-29.

35 McLaughlin, J. P. (1997) 'Why is IMC taking so long? Blame it on the clients', Marketing News, Vol. 31, No. 19, pp. 27-30.

36 Wood, M. B. (1997) 'Clear IMC goals build strong relationships', Marketing News, Vol. 31, No. 13, pp. 11-15.

37 Schultz, D. E. (1999) 'Manage customers, not loyalty programs', Marketing News, Vol. 33, No. 1, pp. 35-36.

38 Kitchen, P. J., Jenkinson, A. and Sain, B. (2004) 'Integrated marketing communications: The next step', in Veloutsou, C. (ed.), ' Communicating with Customers: Trends and Developments', Chapter 13, Athens Institute for Education and Research (ATINER), Athens, pp. 197-216.

39 Schultz and Kitchen (2000). op. cit.

40 Kitchen, Jenkinson and Sain (2004). op. cit.

41 Iacobucci, D. and Calder, B., (eds.), (2003) 'Kellogg on Integrated Marketing', John Wiley \& Sons Inc, Hoboken, NJ.

42 Jenkinson, A. and Sain, B. (2004c) 'Integrated Marketing: A New Vision', Marketing MindPrints, Palgrave-Macmillan, Basingstoke and New York.

43 Green, L. (ed.), (2005) 'Advertising Works and How', WARC, Henley on Thames, pp. 204-219.

44 Jenkinson, A., Sain, B. and Bishop, K. (2005a) 'Optimising communication for charity brand management', International Journal of Voluntary Sector and Nonprofit Marketing, Vol. 10, No. 2, pp. $79-92$.

45 Jenkinson, A., Mathews, B. and Sain, B. (2005b) 'How to win with customers, integrated marketing and its effectiveness', Centre for Integrated Marketing; available at: http://www. stepping-stones.org/Winning_with_Customers.htm (accessed 22nd March, 2006).

46 Schultz and Kitchen (2000). op. cit.

47 McLaughlin (1997). op. cit.

48 Jenkinson (2000). op. cit.

49 Billet (2002). op. cit.

50 Jenkinson and Sain (2004b). op. cit.

51 Billet (2002). op. cit.

52 Smith, A. (1997) 'Integrated marketing communications starts with print plus television', in Proceedings of ESOMAR Latin American Conference, Rio do Janeiro, May, pp. 237-249. 
53 Weser, A. (1997) 'Advertising increases market shares and media mix achieves most: The proof', Paper presented at WerbeWert '97, European Society for Opinion and Marketing Research, Lisbon, November.

54 Christopher, et al. (1991) op. cit.

55 Fill, C. (2002) 'Marketing Communications: Contexts, Strategies and Applications', 3rd edn, Prentice Hall, London.

56 Pech, R. and Slade, B. (2004) 'Memetic Engineering: A Frame-work for Organisational Diagnosis and Development', Graduate School of Management, La Trobe University, Melbourne.

57 Jenkinson, A. (2000). op. cit.

58 Jenkinson, A. and Sain, B. (2004b). op. cit.

59 Reichheld, F. F. (1996) 'The Loyalty Effect', Harvard Business School Press, Boston, MA.

60 Grant, J. (2002) 'After Image: Mind Expanding Marketing', Profile Business Books, HarperCollinsBusiness, London.

61 Seidman, I. (1998) 'Interviewing as Qualitative Research', 2nd edn, Teachers College Press, New York, NY.

62 Jenkinson and Sain (2004a). op. cit.

63 Jenkinson, et al. (2005b). op. cit.

64 Jenkinson and Sain (2005a). op. cit.

65 For more detail, see Jenkinson, A. and Sain, B. (2004d) 'Open Planning, The Problem', MNP Best Practice Group/Centre for Integrated Marketing/CIM, UK.

66 Lloyd, C. V. (1999) 'Advertising media: A changing marketplace', in Jones, J.P. (ed.), ' The Advertising Business', Sage Publications, Thousand Oaks, CA and London.

67 IPA (2002) 'Budweiser, frogs, lizards, whassup? Market share that's what' IPA Effectiveness Awards; IPA, Parkes, L. and Binet, L. (2002) 'Marmite, please don't spread it thinly', IPA Effectiveness Awards. Both available to IPA members on http:// www.ipa.co.uk/awards/databank.cfm or via WARC at http:// www.warc.com/Search/WordSearch/WordSearch.asp.

68 Jenkinson, A. and Sain, B. (2005b) 'SEEBOARD Energy, integrated marketing transforms the brand fortunes', in PMA Educational Foundation (eds) 'ROI of Integrated Marketing', PMA Educational Foundation, New York, NY, pp. 118-163.

69 Jenkinson, et al. (2005a). op. cit.

70 Cowley, D. (2002) 'Strategy \& creative - Two faces of the same coin', Campaign Media Neutral Planning Supplement, November.

71 Gerin, R. (1997) 'Integrating attitudinal and behavorial tools to optimise communications', ESOMAR, Amsterdam, The Netherlands.

72 Kaye, T. (2002) 'MNP just today's buzzword?' Campaign Media Neutral Planning Supplement, November, UK.

73 For example, Ogilvy, D. (1995) 'Ogilvy on Advertising', Prion Books, London.

74 For example, Jenkinson, A. and Sain, B. (2003) 'IDM communicates, clutter? What clutter?, Centre for Integrated Marketing, www.IntegratedMarketing.org.uk (accessed 22nd March, 2006).

75 Jenkinson, A. and Sain, B. (2004e) 'WRC, on track to being a top sports entertainment brand', Centre for Integrated Marketing.

76 IPA (2002) 'The road to purchase, the growth of Volkswagen UK, 1995-2001', IPA Effectiveness Awards. Available to IPA members on http://www.IntegratedMarketing.org.uk(accessed 22nd March, 2006).

77 Wood, K. (2002). Campaign Media Neutral Planning Supplement, November.

78 Mills, D. (2002) 'Editorial', Campaign Media Neutral Planning Supplement, November, UK.
79 Dawson, N. and Ellyatt, M. (2002). Campaign Media Neutral Planning Supplement, November, UK.

80 Jenkinson, et al. (2005b). op. cit.

81 Jenkinson and Sain (2004a). op. cit.

82 Lavidge, R. J. and Steiner, G. A. (1961) 'A model for predictive measurements of advertising effectiveness', Journal of Marketing, Vol. 25 (October), p. 61.

83 Strong, E. K. (1925) 'The Psychology of Selling', McGraw-Hill, New York, NY

84 McGuire, W. J. (1978). 'An information processing model of advertising effectiveness', in Davies, H.L. and Silk, A.J. (eds.), 'Behavioural and Management Science in Marketing', New York, NY, Roland Press, pp. 158-80.

85 Jenkinson (2000). op. cit.

86 Reichheld (1996). op. cit.

87 Vakratsas, D. and Ambler, T. (1999) 'How advertising works: What do we really know?' Journal of Marketing, Vol. 63(January), pp. 26-43.

88 Pine II, B. J. and Gilmour, J. H. (1999) 'The Experience Economy, Work is Theatre and Every Business a Stage', HBS Press, Boston, MA.

89 Peppers, D. and Rogers, M. (1993) 'The One-to-One Future, Building Business Relationships One Customer at a Time', Judy Piaktus Ltd, London.

90 Wright, P. L. (1973) 'The cognitive processes mediating the acceptance of advertising', Journal of Marketing Research, Vol. 10(February), pp. 54-62.

91 Greenwald, A. (1968) 'Cognitive learning, cognitive response to persuasion and attitude change', in Greenwald A., Brook T.C., Ostrom T.W. (eds.), 'Psychological Foundations of Attitudes', Academic Press, New York, NY, pp. 147-169.

92 Jenkinson, et al. (2005a). op. cit.

93 Jenkinson and Sain (2005b). op. cit.

94 Jenkinson and Sain (2004d). op. cit.

95 Jenkinson and Sain (2005b). op. cit.

96 See, for example, case studies by Jenkinson, A. and Sain, B. (2003a) 'Lush, the scent of success', (2003b) 'The Automobile Association: How a big idea put the AA back together'; (2003c) 'Specsavers - An innovative integrated marketing model'; (2005c) 'Amazon: Bonding customers with integrated service', from Centre for Integrated Marketing, www. IntegratedMarketing.org.uk (accessed 23rd March, 2006).

97 Jenkinson, A. and Sain, B. (2005) 'Sainsbury's, little ones', in 'ROI of Integrated Marketing', PMA Educational Foundation, New York, NY, pp. 185-198.

98 Jenkinson, A. and Sain, B. (2004e). op. cit.

99 Jenkinson, A. and Sain, B. (2004f) 'Boots No. 7', Intelligent Media Planning, available at: www.IntegratedMarketing.org.uk (accessed 22nd March, 2006).

100 Jenkinson and Sain (2005b). op. cit.

101 Jenkinson, et al. (2005a). op. cit.

102 Kent, M. (2004) 'Team Vodafone', Paper presented at Centre for Integrated Marketing Conference, 25th March, IBM South Bank, London.

103 Jenkinson, et al. (2005a). op. cit.

104 Bishop, K. (2004) 'Establishing IBM in the high value space we have chosen to lead', Paper presented at Centre for Integrated Marketing Conference, 25th November, London.

105 Bishop, K. and Jenkinson, A. (2004) 'Open planning: Optimising communications and the implications, for direct', Paper presented at IDM members conference, 21st October, London; available at: http://www.openplanning.org/index.php?pgId=3 (accessed 28th October, 2005). 